\title{
Maricel Mayor Marsán. Rumores de suburbios. Miami: Ediciones Baquiana, 2009, 78 pp.
}

Impreso a fines de 2009, pero distribuido a partir de 2010, Rumores de suburbios es la última de las publicaciones poéticas de la escritora cubana, residente desde hace muchos años en Miami, Maricel Mayor Marsán, a quien debemos una copiosa bibliografía en la que se registran conjuntos de poesía, obras teatrales, estudios filológicos, ensayos, libros de texto y aun otras modalidades discursivas. No podemos aquí hacernos eco de las referencias bibliográficas de todas las opciones intelectuales cultivadas, pero sí procede anotar que, con anterioridad a Rumores de suburbios, la obra poética de esta autora ha estado jalonada por diversas e interesantes entregas desde mediados de los años ochenta, en que editó Rostro cercano (1986), hasta Poemas desde Church Street (2006), y comprendiendo, en esos cuatro lustros, libros como Un corazón dividido. A Split Heart (1998), Errores y horrores. Sinopsis histórica poética del siglo XX (2000) y En el tiempo de los adioses (2003).

Ante la dificultad de hacerse con la consulta directa de todos o al menos algunos de estos títulos, remito, al lector interesado, a una útil antología de las obras citadas, la selección que lleva por título Desde una plataforma en Manhattan, y que prologó la poeta, narradora y traductora mejicana Dana Gelinas. Fue impresa en 2008 en México, por Ediciones Fósforo. Merced a la lectura de los textos de esa recopilación, y gracias también al excelente prólogo que los precede, pueden ser apreciadas algunas de las claves sustanciales de la lírica de esta poeta cubana, cuyas preocupaciones más características, conforme señalaba la prologuista, han sido y son el transcurso del tiempo, la barbarie y el anhelo de vivir una vida más digna, y por digna, no sometida a tiranía alguna.

Por nuestra parte, añadiremos a estos trazos el de la plasmación mayormente realista de la escritura poética, la dimensión cívica, ética y moral, y la capacidad evocativa y nostálgica, aspectos estos últimos que se perciben con nitidez en Poemas desde Church Street, un conjunto en el que el lector encontrará diversos poemas muy excelentes. Quien se adentre, en efecto, por las páginas de dicho libro se admirará ante textos de notable valía literaria, entre ellos "A la hora de todas las horas", o bien "Imanil, el asistente de mesero", y podrá leer asimismo, y a mayores, creaciones que no titubeo en calificar como memorables, por ejemplo "Llanto de un amor insomne" y "Canción al recuerdo que habita". Solo por las composiciones referidas, Poemas desde Church Street ya merece ser considerado uno de los mejores y más interesantes libros de poesía de Maricel Mayor Marsán.

Rumores de suburbios comprende cinco secciones, siendo la inicial la más extensa, y la última la más breve. El título de la obra procede de la primera de ellas, "Suburbios", sección a la que suceden otras cuatro, y con las titulaciones que siguen: "Intimidades", "Contemporáneas", "Tristezas" y "Soleadas". Cada una de las partes la conforman textos que, como suele ser típico en la autora, no se ajustan a unas métricas predeterminadas, sino que se configuran libremente en su ritmo y en el diseño de su contorno. Otro rasgo que singulariza a Mayor Marsán consiste en introducir en no pocos poemas algunos sonsonetes ripiosos que a priori parecen un tanto inusitados, pero cuya utilización debe tener algún sentido especial, porque de otro modo no se entendería su empleo reiterado. Confieso que no siempre alcanzo a calibrar la función de tales ripios en varias ocasiones, aunque en distintas oportunidades resultan muy efectistas, e incluso conllevan una irónica sorna, como en el supuesto de la machacona rima en -ente de "El celofán de la liberada":

Toda la historia intrascendente de tu paso clemente por esta tierra ingente se revolvió en una idea ardiente por algunos llamada demente, Un movimiento para la mujer corriente.

Develabas tu sostén y tu mente. De la mano las dos Juanas, la Juana de Arco valiente y la Sor Juana Inés de la Cruz sapiente. 
Justa misión, clara y presente

se hizo paso, decidida y fehaciente.

¡Oh, mujer!...¡Oh qué bien! (p.24)

A mi entender, esta clase de ripiosidades se prodiga en un determinado tipo de discurso de la poeta cubana, justamente el discurso irónico aplicado a una de sus facetas temáticas, la de la censura cívica y moral. No afirmo que el procedimiento no se dé en otras clases de composiciones, pero es en las recién citadas donde su pertinencia resulta más inequívoca. Por no abandonar todavía el campo de la métrica, señalaré también algunas excepcionalidades de Mayor Marsán en este ámbito, y que se registran en Rumores de suburbios, así el comienzo, a base de pareados, del poema que ya se citó, "El celofán de la liberada", o la organización en formato de redondilla con que comienza el texto "La palabra ausente", con el que se abre la sección "Intimidades", y el empleo del estribillo en otro poema del mismo grupo, "Si he de volver a nacer", un estribillo muy logrado ("Si he de volver a nacer/ de mujer quiero volver"), y con gran eficacia sonora en la reiteración silábica en -er, una eficacia que se traslada a la terminación aguda en -ar en los versos de "Motivaciones borinqueñas", en el grupo "Contemporáneas".

Otra característica de Mayor Marsán es su peculiar uso idiomático, pues se vale de un español excelente, aunque influido de vez en cuando por el inglés, idiomas los dos que ella utiliza prácticamente a diario, uno en su ámbito familiar y en su entorno latinoamericano amistoso y cotidiano, y el otro por vivir en los Estados Unidos, y haber de emplearlo en las distintas vicisitudes sociales, empleo que a veces se transparenta en su español, así cuando en un poema como "La reina de los suburbios" se refiere a una mujer que "De vez en cuando visita al psicólogo/ para mejorar su balance mental" (p. 18) y cuyos niños, "Cuando llegan a casa juegan video" (p. 19)

Los rumores suburbiales que se dejan oír en la parte con la que principia el libro no son sino los de Miami, cuyo perfil urbano y cuya idiosincrasia variopinta plasma Mayor Marsán en doce textos en los que se captan diferentes realidades societarias e individuales, muchas de ellas vacuas, y censura la nadería y la incomunicación en la que se sumergen tantas gentes, atrapadas en las trampas de una sociedad consumista como lo es la de USA, en la que se ha sumado la alienación de la tecnología a otras alienaciones ideológicas. El discurso utilizado por la escritora es altamente crítico ante este estado de cosas que también puede detectarse en otros países, sobre todo occidentales. Al ser crítico dicho discurso, es también un discurso moral, aunque no es severo, porque está empapado de ironía, poniendo el acento en la insustancialidad de demasiadas existencias anodinas que viven un día a día sin aporte alguno para el prójimo ni para sí mismas.

Con ser "Suburbios" la sección que da título y sentido al libro, vale la pena reparar en las otras secciones de la obra, porque se dejan leer con complacencia. "Intimidades" hace honor a su titulación, porque la escritora cubana poetiza ahí varios aspectos de su universo más íntimo, en el que tienen cabida, sin que quepa identificar vida y literatura al pie de la letra, el erotismo ("Estoy lista para tu guerra") y la sensualidad "(La sal en tu piel)", pero asimismo otras diferentes dimensiones, entre ellas el compromiso de género. Poema muy bien logrado es "Espacio íntimo", que puede considerarse emblema de toda la sección.

En mi apreciación crítica, conforme con mis gustos estéticos personales, la parte tercera, "Contemporáneas", es la más conseguida de Rumores de suburbios. Los diez poemas que comprende presentan el común denominador de ir dedicados a una decena de mujeres coetáneas de Mayor Marsán, además de ser sus amigas, y de compartir con ellas la actividad intelectual y en la mayor parte de los casos la poesía. Pero el rasgo que, en literatura, es más pertinente lo constituye el orillamiento de la impregnación realista que bañaba la sección primera por entero, y que también aparecía de vez en vez en las demás. A mí no me cabe ninguna duda de que los mejores acentos líricos de la escritora cubana se consiguen justamente en esa faceta de su obra, la que se asienta en su realidad personal, la que explora la amistad, y sobre todo la que indaga en su identidad conflictiva, la de estar escindido su espíritu entre Cuba y los Estados Unidos, además de sentir muy dentro el tirón español de algunos de sus antepasados. En esos poemas en los que el discurso moral pasa a un segundo plano, y por tanto 
no se requiere ya el empleo del sonsonete irónico, asoman dimensiones poéticas misteriosas que dotan a la palabra literaria de la gran calidad que se percibe en la mayoría de los textos.

En la parte cuarta de Rumores de suburbios hace convivir Mayor Marsán temáticas que han prevalecido en otras secciones de su libro. Textos sobre la conducta moral son, por ejemplo, "Te desconozco mirada" y "El triunfador infeliz", en cuyos versos se reprende severamente la violencia y la humillación contra la mujer, testimoniando su indeclinable compromiso de género. El desgarro que en tantas y tantas familias ha provocado la situación política cubana se hace patente en dos composiciones, las dos in memoriam. Una es la "Elegía para una diosa tropical", único poema del libro que está fechado con toda precisión (las 5 de la tarde del 22 de julio de 2003), y que fue compuesto muy pocos días después de fallecer, en su hogar de Nueva Jersey, la cantante Celia Cruz. En él se rinde tributo desde Miami, capital estadounidense del exilio cubano, a la gran guarachera que hubo de vivir alejada de su patria. El otro poema aludido lo dedica su autora a su abuela cántabra, Vida Rodríguez Gómez, cuyo destino fue también la lejanía, el desgajamiento familiar y la soledad, víctima de las circunstancias políticas de Cuba, que un día fue su tierra de acogida.

La quinta sección, "Soleadas", consta de tres poemas dedicados a tres países del Caribe insular: Cuba, Puerto Rico y República Dominicana. Horizontes luminosos los tres, "Tributo a Puerto Rico" responde bien al título que lleva, porque lo conforman versos de admiración a las tierras borinqueñas, siendo "Cuba en el mar" la evocación de una isla que conserva fieles recuerdos de la autora, mientras aguarda un mañana bien distinto de aquel con el que ha amanecido durante muchas décadas. Los recuerdos que contiene "Tierra dominicana", muy querida para Mayor Marsán, se plasman en el único texto, bien excelente, que se ha creado como poema en prosa en Rumores de suburbios.

José María Balcells 